\title{
Reimbursed Price of Orphan Drugs: Current Strategies and Potential Improvements
}

\author{
Pierpaolo Mincarone $^{a}$ Carlo Giacomo Leo $^{b, c}$ Saverio Sabina ${ }^{b}$ \\ Antonio Sarriá-Santamera ${ }^{d, e}$ Domenica Taruscio ${ }^{f}$ \\ Pedro Guillermo Serrano-Aguilar ${ }^{\mathrm{e}, g}$ Panos Kanavos $^{\mathrm{h}}$ \\ anstitute for Research on Population and Social Policies, URT Brindisi, National Research Council of Italy, \\ Brindisi, and ${ }^{\mathrm{b}}$ Institute of Clinical Physiology, Branch of Lecce, National Research Council of Italy, Lecce, Italy; \\ 'Department of Medicine, Tufts Medical Center, Boston, MA, USA; ${ }^{\mathrm{d}}$ National School of Public Health, Institute of \\ Health Carlos III, and ' Spanish Network of Health Services Research for Chronic Diseases (REDISSEC), Madrid, Spain; \\ ${ }^{f}$ National Centre for Rare Diseases, National Health Institute, Rome, Italy; ${ }^{g}$ Evaluation Service - Canary Islands Health

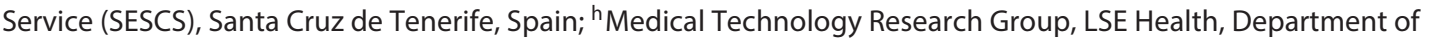 \\ Social Policy, London School of Economics and Political Science, London, UK
}

\section{Keywords}

Access to healthcare $\cdot$ Early dialog $\cdot$ Orphan drugs · Pricing ·

Technology assessment, biomedical [MeSH]

\begin{abstract}
The pricing and reimbursement policies for pharmaceuticals are relevant to balance timely and equitable access for all patients, financial sustainability, and reward for valuable innovation. The proliferation of high-cost specialty medicines is particularly true in rare diseases (RDs) where the pricing mechanism is characterised by a lack of transparency. This work provides an overall picture of current strategies for the definition of the reimbursed prices of orphan drugs (ODs) and highlights some potential improvements. Current strategies and suggestions are presented along 4 dimensions: (1) comprehensive value assessment, (2) early dialogs among relevant stakeholders, (3) innovative reimbursement approaches, and (4) societal participation in pro-
\end{abstract}

\section{KARGER}

(C) 2017 S. Karger AG, Basel

E-Mail karger@karger.com

www.karger.com/phg ducing ODs. Comprehensive value assessment could be achieved by clarifying the approach of distributive justice to adopt, ensuring a representative participation of stakeholders, and with a broad consideration of value-bearing factors. With respect to early dialogs, cross-border cooperation can be determinant to companies and agencies. The cost-benefit ratio of early dialogs needs to be demonstrated and the "regulatory capture" effect should be monitored. Innovative reimbursement approaches were developed to balance the need for evidence-based decisions with the timely access to innovative drugs. The societal participation in producing ODs needs to be recognised in a collaborating framework where adaptive agreements can be developed with mutual satisfaction. Such agreements could also impact on coverage and reimbursement decisions as additional elements for the determination of a comprehensive societal value of

\section{P. Mincarone and C.G. Leo contributed equally to this work.}

Pierpaolo Mincarone, MSc, $\mathrm{PhD}$

Consiglio Nazionale delle Ricerche, Istituto di Ricerca per la Popolazione e le Politiche Sociali, URT Brindisi, c/o ex Osp Di Summa, padiglione centrale, piano 1 stanza 18 Piazza Di Summa, IT-72100 Brindisi (Italy)

E-Mail pierpaolo.mincarone@irpps.cnr.it 
ODs. Further research is needed to investigate the highlighted open challenges so that RDs will not remain, in practical terms, orphan diseases.

(c) 2017 S. Karger AG, Basel

\section{Introduction}

Across the countries belonging to the Organisation for Economic Co-operation and Development (OECD), pharmaceutical spending in 2013 reached almost 20\% of total health spending on average, equivalent to $1.4 \%$ of gross domestic product [1]. As reported in that OECD report, the proliferation of high-cost medicines is expected to be a major driver of health spending growth in the coming years, although some of these new medicines provide only marginal health benefits [1]. In this context, pricing and reimbursement policies are relevant to ensure a balance among timely and equitable access for patients, financial sustainability of publicly funded health systems, and valuing of industrial innovation [2,3]. High prices are observed in therapeutic areas such as cancer, multiple sclerosis, pulmonary disease, hepatitis $\mathrm{C}$, rheumatic diseases, and rare and ultra-rare diseases [1]. In the specific case of orphan drugs (ODs), while regulations have stimulated research and development of orphan medicinal products [4], equitable and timely access to approved ODs for rare diseases (RDs) remains an issue, and effective market access and utilisation vary strongly between and within states $[5,6]$. Additionally, the OD market share for non-generic prescription drugs is expected to increase worldwide from $13.8 \%$ in 2013 to $20.2 \%$ in 2020 [7]. The pricing mechanism for ODs is characterised by a lack of transparency $[6,8,9]$. Up to now, only few descriptive studies have identified some factors characterising ODs' price setting, including (1) the low prevalence of the indication [10], (2) the uncertainties in reaching the expected number of patients [11], (3) the expensive surveillance programmes imposed by regulatory authorities for fast-tracked to market ODs [12], and (4) the absence of alternative treatments [8].

From a pragmatic perspective, the reimbursed price of drugs results from a negotiation between a pharmaceutical company and the representatives of national health authorities. Pharmaceutical companies often work in monopolistic conditions, especially during the period of market exclusivity $[6,13-15]$. Besides the limited availability of specific information, third-party payer organisations are under pressure from patient advocacy groups and mass media [12], especially in present times where the financial crisis forces governments to apply pricing and reimbursement control measures. These cost containment measures may undermine the continued provision of equitable and comprehensive healthcare for the population as well as health outcomes such as health expectancy and health-related quality of life [16]. In this scenario, value-based pricing plays an important role.

Across national public health systems, well-defined processes are in place to support decision makers in setting value for money of new health technologies [17] coming into the market. Health technology assessment (HTA) [18], as described by Lampe et al. [19], is intended to identify, appraise, and synthesise all available scientific evidence to inform decisions considering 10 different domains: characterisation of the specific health problem and existing current treatment alternatives; description of the technology under scrutiny; evidence on safety, clinical effectiveness (comparative effectiveness), and costeffectiveness; budget impact analysis; ethical analysis; and considerations of organisational, social, and legal issues. In the case of ODs, several of the above-reported domains become critical [9, 12, 20-25], feeding an open worldwide debate about the appropriateness of existing HTA methods for health technologies devoted to RDs [26-29]. Increasingly, considerations of using an extended set of criteria beyond the conventional core assessment of safety, efficacy, and cost-effectiveness is gaining acceptance even among the HTA community [30-32].

The aim of this paper was to provide an overall picture of current strategies for the definition of the reimbursed prices of ODs, identifying current strategies and potential improvements.

\section{Discussion}

Reimbursed Price of ODs: Current Strategies and Potential Improvements

The current strategies for OD reimbursement are classified according to a conceptual framework with 4 dimensions (Fig. 1): (1) comprehensive value assessment, (2) early dialogs among relevant stakeholders (i.e., before phase III clinical trial), (3) innovative reimbursement approaches to allow timely access to ODs, and (4) societal participation in producing ODs.

\section{Comprehensive Value Assessment}

Current discussions on financing ODs deal with principles of priority setting based on distributive justice, involvement of stakeholders along the evaluation process,
2

Public Health Genomics 2017;20:1-8 DOI: $10.1159 / 000464100$
Mincarone/Leo/Sabina/Sarriá-Santamera/ Taruscio/Serrano-Aguilar/Kanavos 
Fig. 1. Conceptual framework for analysing current strategies for pricing definition.

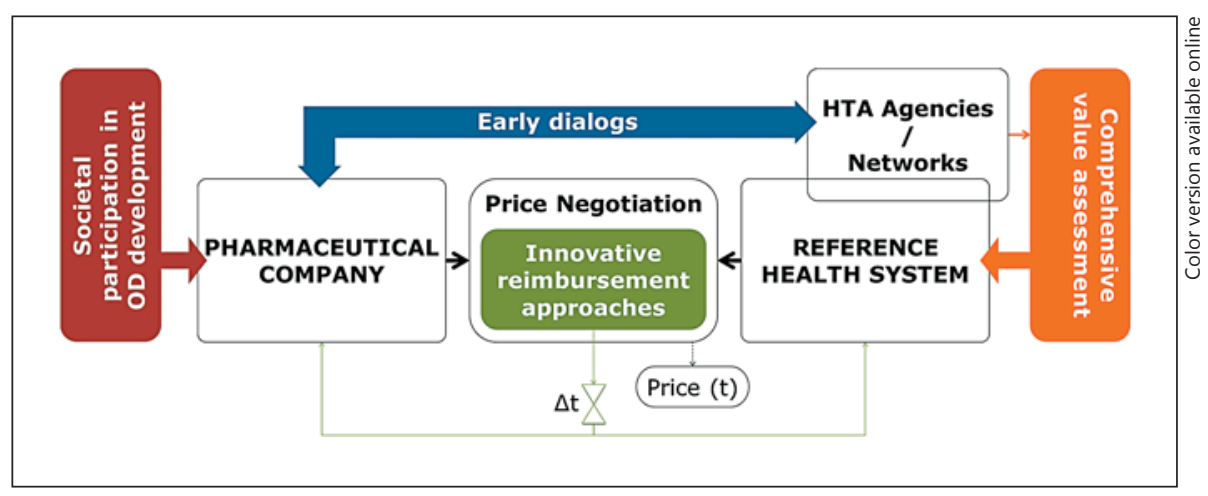

and value-bearing factors and their combination for a comprehensive assessment [22, 33-35].

Priority setting involves complex value-laden choices that are often socially, ethically, and politically controversial, implying opposite interests for different stakeholders, including government officials, pharmaceutical companies, patient, and the public [22]. Two main and contrasting principles can be distinguished: the utilitarian approach (i.e., healthcare resources are distributed so as to achieve maximum "benefit" in terms of population health), and the rule of rescue (i.e., resources are only assigned to satisfy the needs of identifiable groups in serious danger). These 2 principles could converge under a third egalitarian principle of distributive justice focused on reducing "inequalities" among groups [36]. The vulnerability of small patient groups affected by RDs with limited treatment options, commonly supported by incomplete evidence and the uncertainty for ODs in obtaining reasonable returns from industrial investments, might raise the relevance of this third principle of distributive justice $[37,38]$.

Two central components of a legitimate and fair distributive or priority setting process are transparency and stakeholder participation in decision-making [39]. As underlined by Douglas et al. [40], reimbursement decision-making for ODs could benefit from public and patient involvement in the following 3 different types of procedures: HTA, priority setting to address public funding, and development of evaluation criteria. As recognised by Drummond et al. [21], patients could provide valuable information on the satisfaction and acceptability of health technologies and could inform decisions supported from their values, needs, and preferences. The interaction of increased transparency in public health policies, together with the recognition of the value of the patients' experiential expertise, could play a role in involving

Pricing Orphan Drugs public/patient representatives in coverage decision-making, either directly or indirectly by means of setting and weighing specific criteria to support coverage decisionmaking [21, 40].

Although there is agreement in considering a broader approach to set the value of pharmaceuticals in general, including their societal value, and regardless of some pilot experiences which are currently under development, there is no internationally agreed-on taxonomy for valuebearing criteria or measuring instruments $[26,32,33,41-$ 43]. Despite these limited advances, different factors have been considered for value-bearing pharmaceuticals, including the disease and patient characteristics, the possibility of improvement either in health (effect size for efficacy and safety) or non-health outcomes (procedural attributes) [44], and the increasingly recognised value of innovation $[45,46]$. Though some other issues could be considered in the specific field of RDs and ODs - such as rarity and disease severity, lack of suitable treatment alternatives, evidence of efficacy and safety, degree of product innovation, societal therapeutic impact, and potential drug use for more than 1 indication -, they are not consistently used in value assessments for coverage decisions of ODs [26, 32, 42, 47, 48].

A taxonomy of approaches to value-based pricing, spanning elements of value, measuring techniques, and aggregating approaches, has been proposed by Sussex et al. [45], who also piloted an application of multi-criteria decision analysis (MCDA) for assessing potential public reimbursement and valuing ODs. They concluded that, given the intrinsically complex nature of the $\mathrm{RD}$ and $\mathrm{OD}$ environment, an MCDA approach has the merit of ensuring transparency, reproducibility, participation, and a shared understanding of all the elements of value, with the possibility of balancing the trade-offs between them. Also, the World Health Organization (WHO) recognises

Public Health Genomics 2017;20:1-8 DOI: $10.1159 / 000464100$ 
MCDA as a more holistic approach to assess the overall value of medicines under a wider spectrum of stakeholder participation, with the aim of balancing different and potentially opposing interests [49]. In 2014, the International Society for Pharmacoeconomics and Outcomes Research (ISPOR) established an Emerging Good Practices Task Force to standardise MCDA use to assess potential public reimbursement of drugs. To date, the task force has produced 2 reports: the first one defines MCDA, providing an overview of the main alternative methods and steps with examples for its use in healthcare [50]. The second report provides emerging good practice recommendations to guide the implementation of MCDA to support health policy decisions [51].

However, current funding recommendations from most HTA agencies are still mainly based on the incremental cost-effectiveness ratio - the incremental cost per quality-adjusted life year gained by treated patient. As Thokala and Duenas pointed out in 2012 [52], even though HTA agencies occasionally consider other criteria, such as severity and life-saving together with incremental cost-effectiveness ratios, there is concern that this approach may fail to capture other important sources of value. A paper recently published by Kanters et al. [53], focused on Pompe disease, illustrates the great variability in reimbursement decisions of ODs between European countries. As these authors state, it is not possible to know "how much the differences in reimbursement decisions between countries result from differences in the assessment and appraisal phase," calling for more transparency and reproducibility in decision-making. Supporters of these changes argue that although the adoption and funding decisions of ODs are complex and multidimensional, the criteria used are unknown, inconsistently applied, and involve value judgments. Consequently, some HTA agencies are considering MCDA to manage participation of a variety of stakeholders with different interests and values, according to a more explicit and rational, participative, reproducible, and transparent framework to inform decisions $[52,54]$. To that end, the European Union Committee of Experts on Rare Diseases (EUCERD) gave clear indications to the European network for Health Technology Assessment (EUnetHTA) to involve patients, clinicians, researchers, and industry representatives in the process of reviewing and adapting the assessment methods described in the network Core Model ${ }^{\circledR}$ $[19,55]$, specifically for ODs [5]. Under these common European methodological recommendations, national agencies could shape their final decisions based on local specificities (disease incidence and prevalence, severity, treatment patterns, drug prices, absolute and relative treatment costs, budget impact, and/or cost-effectiveness). Other methodological issues should be considered in the specific field of RDs and ODs, such as the use of evidence provided by real-world data [31], the acceptance of intermediate or surrogate outcomes, and the adoption of off-label drugs or best supportive care as comparators. Different authors analysed possible barriers and critical success factors for the implementation of cross-border assessments in Europe and reported that autonomy in decision-making of healthcare coverage is a politically sensitive issue $[56,57]$. Some of the identified success factors include the early agreement on topic selection and scope definition for assessment, a methodological framework flexible enough to fit demands/capacities from individual countries, voluntary use at the national level of the common assessment framework, the necessity to build trust among participating countries, and the need of relying on transparent and high-quality processes to get valid outputs.

\section{Early Dialogs}

A critical element of uncertainty is represented by the amount and quality of information provided by the pharmaceutical company both to HTA agencies and health authorities when dealing with assessment and pricing activities, respectively. A current challenge is to set adequate alternatives and procedures for information exchanging on study design, selection of outcome measures, and measurement instruments from earlier stages of research and development of drugs (i.e., before phase III clinical trials) [58]. Current efforts are implemented by regulatory, HTA, and/or coverage bodies to look for shared common objectives with the industry, providing scientific advice and anticipating information on procedures, requirements, and plans, and aligning time frames and other logistical aspects of the review processes [59-66]. In this contest, for example, the EuroScan International Network supports the early dialog between manufacturers, evaluators, and health services by identifying technologies and their developers before evidence has been generated [67]. In the specific case of ODs, EUCERD promoted the use of early dialogs between the industry, the European Medicines Agency, and EUnetHTA members/ HTA bodies, with particular emphasis on anticipating requirements and developing a continuum and easy interactions between HTA processes and regulatory issues [5]. Despite the growing consensus, uncertainty remains on the real value of these strategies to improve patients' health expectations in a sustainable manner for public
4

Public Health Genomics 2017;20:1-8 DOI: $10.1159 / 000464100$
Mincarone/Leo/Sabina/Sarriá-Santamera/ Taruscio/Serrano-Aguilar/Kanavos 
health services [61]. Some of the questions waiting for answer we believe to apply also to ODs are: Who should fund the human resources needed to support these longterm activities? Might the closer contact and maintained interaction between industry and regulatory/assessment bodies introduce some degree of decisional bias (increased sensitivity to the concerns of manufacturers in detriment of consumers interest - "regulatory capture")? How should conflicting advice be dealt with (e.g., in case of tri-partite advice covering both regulatory and coverage issues) $[58,68]$ ?

\section{Innovative Reimbursement Approaches}

Various innovative reimbursement schemes are increasingly being adopted to answer to the need of faster patient access to potentially beneficial technologies. Cost containment strategies to warrant the sustainability of publicly funded health systems, when evidence is limited and there is uncertainty at the time of market introduction, are being explored [69]. Reimbursement for ODs can be granted either under the commitment of assessing clinical performance by means of relevant health outcomes - "conditional reimbursement linked to performance" and "coverage with evidence development" - or by stemming the budget impact (financially based schemes) - "price-volume" and "per patient utilisation caps" [70-72]. These reimbursement mechanisms have been categorised as managed entry agreements (MEAs) or market access agreements [73]. While conditional reimbursement schemes linked to performance are addressed to avoid inefficient expenditure on treating individual patients who do not respond to a drug and who cannot be previously identified [6], coverage with evidence development schemes looks for new evidence to reduce uncertainty about a drug's real-life effectiveness in a cohort of patients [72]. Financially based schemes are all forms of commercial agreements taking a variety of forms, including cost capping, utilisation capping, and free and/or discounted initiation. They aim at reducing expenditures for the healthcare payer on costly drugs without collecting real-life health data from patients [6].

Given the limited effectiveness evidence for MEAs in the real world, improvements in transparency for their rationale, objectives, scope, methods for review, information collected, criteria for ending, and results of the agreement (e.g., target expenditure/use versus achieved expenditure/use, increased level of evidence) should be encouraged [74]. Besides, as suggested by the ISPOR [72], studies on MEAs should consider the value of reduced uncertainties against additional direct costs (for the negotiation,

Pricing Orphan Drugs monitoring, and evaluation phases) and the existence of any irreversibility in the process (e.g., difficulties regarding the withdrawal of a product). In the specific field of ODs, some additional considerations should be targeted, such as development of shared patient registries to enable secondary data analysis, adaptive pathways, and crossborder data pooling in order to provide valid data not limited by sample sizes issues $[69,74,75]$. Campbell et al. [76] proposed a more comprehensive procedure, supported by tools including quality indicators, to improve the assessment and potential adoption of new medicines.

\section{Societal Participation in Producing ODs}

Beyond health authorities and the industry, other stakeholders might be considered along the process of valuing pharmaceuticals for reimbursement purposes. Besides existing healthcare and research infrastructures, physicians collaborating in clinical trials on behalf of their patients and the scientific community producing the basic knowledge on diseases, an increasingly significant role is played by individual patients who share their experiences and risk their own health by participating in research programs [35]. As pointed out by Paulden et al. [32], socioeconomic policies together with access to diagnosis and treatment facilities are key elements in the final success of coverage decision for ODs. Moreover, disease advocacy groups not only contribute to accelerate research and product development, but are generally active in informing patients about new treatments, hence contributing to decrease marketing costs [77]. All these stakeholders might be considered for participating in some stages of valuing pharmaceuticals prior to the pricing processes. Patients could adequately represent their needs if involved, through patient/parent associations, in valuing drugs and informing about price setting. To satisfy this aim, the general methodological framework suggested by Tunis and Pearson [70] should be adapted to the specificities of RDs and ODs. The support provided to the pharmaceutical companies by public institutions, from early dialogs and scientific collaborations, should be planned in advance under agreements supported by future compensations. Royalties could be granted by companies to fund/support institutions/organisations in order to compensate them for their contributions to OD development. A different but related point is the issue of access to patented knowledge generated with the support of tertiary funds (either public or from advocacy groups). As reported by Lee [78], public institutions, non-profit organisations, and disease advocacy groups are increasingly conditioning their contributions to biomedical re-

Public Health Genomics 2017;20:1-8 DOI: $10.1159 / 000464100$ 
search on the beneficiary commitment of sharing the likely patented inventions for non-commercial research purposes. We suggest that those pharmaceutical companies allowing further research utilisation of patented ODs by public/non-profit research institutions get an improved valuation for public coverage and reimbursement purposes. In fact, this could be an additional criterion to consider if MCDA is used for public approval and valuebased pricing.

According to O'Sullivan et al. [35], a model of reduced profitability is ethically responsible and institutionally plausible, particularly for lifelong therapies, but will require pharmaceutical companies to develop new models and educate investors about the long-term advantage of regaining public trust. Pharmaceutical companies may consider that working with reduced profitability to serve society (as can be the case for ODs) may allow them to achieve a competitive advantage in the long term if done with a strategic orientation of corporate social responsibility [79].

\section{Conclusion}

Coverage decisions for ODs are complex and subject to dynamics in several conflicting factors, such as promoting timely and equitable access for patients, cost-containment strategies to sustain public healthcare services, and rewarding innovation. We wish to stimulate the debate on a comprehensive approach in the definition of health policies for ODs. We suggest to integrate the principles of distributive justice with greater process transparency and public participation, to use multiple criteria to support analysis and pharmaceutical coverage decisions, to further explore the potential of early dialogs and inno- vative reimbursement approaches to fully understand their benefits and costs, and to apply adaptive agreements supporting future compensations to subjects contributing to the early phases of OD development. Further research is needed to investigate the open challenges so that RDs will not remain, in practical terms, orphan diseases. Addressing the discussed topics and working on the highlighted research questions becomes even more urgent as long as the advancements in the science of genomics drive an increase in personalised medical treatments gaining a quasi-orphan status.

\section{Acknowledgement}

The authors wish to thank David Tordrup for his valuable suggestions in the designing of the work and Roberto Guarino (National Research Council, Institute of Clinical Physiology) who collaborated in drawing the figure.

\section{Disclosure Statement}

The authors declare that they have no competing interests.

\section{Author Contributions}

P. Mincarone and C.G. Leo equally contributed to the work. They conceptualised and planned the study, reviewed the literature, participated in the phase of discussion on results and proposals, and drafted the initial manuscript. S. Sabina, D. Taruscio, A. SarriáSantamera, and P. Serrano-Aguilar participated in the conceptualisation of the study and in the phase of discussion and critically reviewed the manuscript. P. Kanavos critically reviewed the planning of the study, participated in the discussion, and critically reviewed the manuscript. All authors read and approved the final manuscript and agree to be accountable for all aspects of the work.

\section{References}

1 OECD (2015): Health at a Glance 2015: OECD Indicators, OECD Publishing, Paris. DOI: http://dx.doi.org/10.1787/health_ glance-2015-en.

2 Pharmaceutical Forum - Pricing and Reimbursement Working Group: Improving access to orphan medicines for all affected EU citizens. Final conclusions and recommendations of the pharmaceutical forum. 2014. Accessible at http://ec.europa.eu/DocsRoom/ documents/7586/attachments/1/translations/en/renditions/pdf.
3 Vozikis A, Cooper DN, Mitropoulou C, Kambouris ME, Brand A, Dolzan V, Fortina P, Innocenti F, Lee MT, Leyens L, Macek M Jr, AlMulla F, Prainsack B, Squassina A, Taruscio D, van Schaik RH, Vayena E, Williams MS, Patrinos GP: Test pricing and reimbursement in genomic medicine: towards a general strategy. Public Health Genomics 2016;19:352363.

4 Murakami M, Narukawa M: Matched analysis on orphan drug designations and approvals: cross regional analysis in the United States, the European Union, and Japan. Drug Discov Today 2016;21:544-549.
5 European Union Committee of Experts on Rare Diseases (EUCERD): EUCERD recommendation for a CAVOMP information flow. Accessible at http://www.eucerd.eu/?post_ type $=$ document $\& p=1446$.

6 Gammie T, Lu CY, Babar ZU: Access to orphan drugs: a comprehensive review of legislations, regulations and policies in 35 countries. PLoS One 2015; 10:e0140002.

7 EvaluatePharma: Orphan drug report 2015. Accessible at www.evaluategroup.com/Orphandrug2015. 
8 Picavet E, Morel T, Cassiman D, Simoens S: Shining a light in the black box of orphan drug pricing. Orphanet J Rare Dis 2014;9:62.

9 Schey C, Milanova T, Hutchings A: Estimating the budget impact of orphan medicines in Europe: 2010-2020. Orphanet J Rare Dis 2011;6:62.

10 Messori A, Cicchetti A, Patregani L: Orphan drugs. Relating price determination to disease prevalence. BMJ 2010;341:c4615.

11 Tambuyzer E: Rare diseases, orphan drugs and their regulation: questions and misconceptions. Nat Rev Drug Discov 2010;9:921929.

12 Simoens S: Pricing and reimbursement of orphan drugs: the need for more transparency. Orphanet J Rare Dis 2011;6:42.

13 European Commission: Regulation (EC) No 141/2000 of the European Parliament and of the Council of 16 December 1999 on orphan medicinal products. Official Journal of the European Communities 2000, L 18/1. Accessible at http://eur-lex.europa.eu/LexUriServ/ LexUriServ.do?uri=OJ:L:2000:01 8:0001: 0005:en:PDF.

14 US FDA: The orphan drug regulations. Final rule, 78 FR 3511721 CFR Part 316 2013, pp 35117-35132.

15 Orphanet: Worldwide comparison of regulation 2001. Accessible at http://www.orpha. net/consor4.01/www/cgi-bin/Education_EducationTools.php? lng $=$ EN\&stapage $=S T_{\text {_ }}$ EDUCATION_EDUCATION_ABOUTORPHANDRUGS_COMPARISON (accessed June 17, 2014).

16 Godman B, Malmström RE, Diogene E, Gray A, Jayathissa S, Timoney A, Acurcio F, Alkan A, Brzezinska A, Bucsics A, Campbell SM, Czeczot J, de Bruyn W, Eriksson I, Yusof FA, Finlayson AE, Fürst J, Garuoliene K, Guerra Júnior A, Gulbinovič J, Jan S, Joppi R, Kalaba M, Magnisson E, McCullagh L, Miikkulainen K, Ofierska-Sujkowska G, Pedersen HB, Selke G, Sermet C, Spillane S, Supian A, Truter I, Vlahović-Palčevski V, Vien LE, Vural EH, Wale J, Władysiuk M, Zeng W, Gustafsson LL: Are new models needed to optimize the utilization of new medicines to sustain healthcare systems? Expert Rev Clin Pharmacol 2015;8:77-94.

17 WHO Executive Board: 121st session. Health technologies. Report by secretariat. EB121/11 2007. Accessible at http://apps.who.int/gb/ archive/pdf_files/EB121/B121_11-en.pdf.

18 Tordrup D, Tzouma V, Kanavos P: Orphan drug considerations in Health Technology Assessment in eight European countries. Rare Dis Orphan Drugs 2014;1:83-97.

19 Lampe K, Mäkelä M, Garrido MV, Anttila H, Autti-Rämö I, Hicks NJ, Hofmann B, Koivisto J, Kunz R, Kärki P, Malmivaara A, Meiesaar K, Reiman-Möttönen P, Norderhaug I, Pasternack I, Ruano-Ravina A, Räsänen P, Saalasti-Koskinen U, Saarni SI, Walin L, Kristensen FB; European network for Health Technology Assessment (EUnetHTA): The HTA core model: a novel method for produc- ing and reporting health technology assessments. Int J Technol Assess Health Care 2009; 25(suppl 2):9-20.

20 Griggs RC, Batshaw M, Dunkle M, GopalSrivastava R, Kaye E, Krischer J, Nguyen T, Paulus K, Merkel PA; Rare Diseases Clinical Research Network: Clinical research for rare disease: opportunities, challenges, and solutions. Mol Genet Metab 2009;96:20-26.

21 Drummond M, Tarricone R, Torbica A: Assessing the added value of health technologies: reconciling different perspectives. Value Health 2013;16(1 suppl):S7-S13.

22 Rosenberg-Yunger ZRS, Daar AS, Thorsteinsdóttir H, Martin DK: Priority setting for orphan drugs: an international comparison. Health Policy 2011;100:25-34.

23 Westermark K, Tsigkos S, Llinares J: Is it time to clarify orphan drug policies? Yes, for equity's sake. BMJ 2010;341:c4777.

24 Niezen MGH, de Bont A, Busschbach JJ, Cohen JP, Stolk EA: Finding legitimacy for the role of budget impact in drug reimbursement decisions. Int J Technol Assess Health Care 2009;25:49-55.

25 Iskrov G, Stefanov R: Post-marketing access to orphan drugs: a critical analysis of health technology assessment and reimbursement decision-making considerations. Orphan Drugs Res Rev 2014;4:1-9.

26 Hughes-Wilson W, Palma A, Schuurman A, Simoens S: Paying for the Orphan Drug System: break or bend? Is it time for a new evaluation system for payers in Europe to take account of new rare disease treatments? Orphanet J Rare Dis 2012;7:74.

27 Simoens S: Health technologies for rare diseases: does conventional HTA still apply? Expert Rev Pharmacoecon Outcomes Res 2014; 14:315-317.

28 Zelei T, Molnár MJ, Szegedi M, Kaló Z: Systematic review on the evaluation criteria of orphan medicines in Central and Eastern European countries. Orphanet J Rare Dis 2016; 11:72.

29 Drummond M, Towse A: Orphan drugs policies: a suitable case for treatment. Eur J Health Econ 2014; 15:335-340.

30 Kolasa K, Zwolinski KM, Kalo Z, Hermanowski T: Potential impact of the implementation of multiple-criteria decision analysis (MCDA) on the Polish pricing and reimbursement process of orphan drugs. Orphanet J Rare Dis 2016;11:23.

31 Iskrov G, Miteva-Katrandzhieva T, Stefanov R: Multi-criteria decision analysis for assessment and appraisal of orphan drugs. Front Public Health 2016;4:214.

32 Paulden M, Stafinski T, Menon D, McCabe C: Value-based reimbursement decisions for orphan drugs: a scoping review and decision framework. Pharmacoeconomics 2014;33: 255-269.

33 Sussex J, Rollet P, Garau M, Schmitt C, Kent A, Hutchings A: A pilot study of multicriteria decision analysis for valuing orphan medicines. Value Health 2013;16:1163-1169.
34 Kanavos P, Nicod E: What is wrong with orphan drug policies? Suggestions for ways forward. Value Health 2012;15:1182-1184.

35 O'Sullivan BP, Orenstein DM, Milla CE: Pricing for orphan drugs: will the market bear what society cannot? JAMA 2013;310:13431344.

36 Cookson R, Dolan P: Principles of justice in health care rationing. J Med Ethics 2000;26: 323-329.

37 McKie J, Richardson J: The rule of rescue. Soc Sci Med 2003;56:2407-2419.

38 National Institute for Health and Care Excellence: Interim process and methods of the Highly Specialised Technologies Programme. Accessible at https://www.nice.org.uk/Media/ Default/About/what-we-do/NICE-guidance/ NICE-highly-specialised-technologies-guidance/Highly-Specialised-Technologies-Interim-methods-and-process-statements.pdf.

39 Rosenberg-Yunger ZRS, Thorsteinsdóttir $\mathrm{H}$, Daar AS, Martin DK: Stakeholder involvement in expensive drug recommendation decisions: an international perspective. Health Policy 2012;105:226-235.

40 Douglas CMW, Wilcox E, Burgess M, Lynd LD: Why orphan drug coverage reimbursement decision-making needs patient and public involvement. Health Policy 2015;119: 588-596.

41 Gutierrez L, Patris J, Hutchings A, Cowell W: Principles for consistent value assessment and sustainable funding of orphan drugs in Europe. Orphanet J Rare Dis 2015;10:53.

42 Platform on Access to Medicines in Europe - Working Group on Mechanism of Coordinated Access to Orphan Medicinal Products (MoCA-OMP): Process on Corporate Social Responsibility in the Field of Pharmaceuticals. Transparent Value Framework. 2013. Accessible at http://ec.europa.eu/DocsRoom/documents/7631/attachments/1/ translations/en/renditions/pdf.

43 Working Group on Mechanism of Coordinated Access to Orphan Medicinal Products (MoCA-OMP): Process on corporate social responsibility in the field of pharmaceuticals platform on access to medicines in Europe. Final Report 2013. Accessible at http://ec.europa.eu/DocsRoom/documents/7629/attachments/1/translations/en/renditions/pdf.

44 Entwistle V, Firnigl D, Ryan M, Francis J, Kinghorn P: Which experiences of health care delivery matter to service users and why? A critical interpretive synthesis and conceptual map. J Health Serv Res Policy 2012;17:70-78.

45 Sussex J, Towse A, Devlin N: Operationalizing value-based pricing of medicines: a taxonomy of approaches. Pharmacoeconomics 2013;31:1-10.

46 UK Department of Health: A new value-based approach to the pricing of branded medicines. Accessible at http://webarchive.nationalarchives.gov.uk/20130107105354/http:/ www.dh.gov.uk/prod_consum_dh/groups/ dh_digitalassets/@dh/@en/documents/digitalasset/dh_122793.pdf. 
47 Drummond MF, Wilson DA, Kanavos P, Ubel P, Rovira J: Assessing the economic challenges posed by orphan drugs. Int J Technol Assess Health Care 2007;23:36-42.

48 Schlander M, Beck M: Expensive drugs for rare disorders: to treat or not to treat? The case of enzyme replacement therapy for mucopolysaccharidosis VI. Curr Med Res Opin 2009;25:1285-1293.

49 World Health Organization Regional Office for Europe: Access to new medicines in Europe: technical review of policy initiatives and opportunities for collaboration and research (2015). Accessible at http://www.euro.who. int/en/health-topics/Health-systems/medicines/publications2/2015/access-to-newmedicines-in-europe-technical-review-ofpolicy-initiatives-and-opportunities-for-collaboration-and-research.

50 Thokala P, Devlin N, Marsh K, Baltussen R, Boysen M, Kalo Z, Longrenn T, Mussen F, Peacock S, Watkins J, Ijzerman M: Multiple criteria decision analysis for health care decision making - an introduction: report 1 of the ISPOR MCDA Emerging Good Practices Task Force. Value Health 2016;19:1-13.

51 Marsh K, Ijzerman M, Thokala P, Baltussen R, Boysen M, Kaló Z, Lönngren T, Mussen F, Peacock S, Watkins J, Devlin N; ISPOR Task Force: Multiple criteria decision analysis for health care decision making - emerging good practices: report 2 of the ISPOR MCDA Emerging Good Practices Task Force. Value Health 2016;19:125-137.

52 Thokala P, Duenas A: Multiple criteria decision analysis for health technology assessment. Value Health 2012;15:1172-1181.

53 Kanters TA, Hakkaart L, Rutten-van Mölken MP, Redekop WK: Access to orphan drugs in western Europe: can more systematic policymaking really help to avoid different decisions about the same drug? Expert Rev Pharmacoecon Outcomes Res 2015;15:557-559.

54 Diaby V, Goeree R, Hoch J, Siebert U: Multicriteria decision analysis for health technology assessment in Canada: insights from an expert panel discussion. Expert Rev Pharmacoecon Outcomes Res 2015;15:13-19.

55 European network for Health Technology Assessment: HTA Core Model ${ }^{\circledR}$. Accessible at http://www.eunethta.eu/hta-core-model (accessed March 6, 2014).

56 Kleijnen S, Toenders W, de Groot F, Huic M, George E, Wieseler B, Pavlovic M, Bucsics A, Siviero PD, van der Graaff M, Rdzany R, Kristensen FB, Goettsch W: European collaboration on relative effectiveness assessments: what is needed to be successful? Health Policy 2015;119:569-576.

57 Leyens L, Brand A: Early patient access to medicines: health technology assessment bodies need to catch up with new marketing authorization methods. Public Health Genomics 2016;19:187-191.
58 Backhouse ME, Wonder M, Hornby E, Kilburg A, Drummond M, Mayer FK: Early dialogue between the developers of new technologies and pricing and reimbursement agencies: a pilot study. Value Health 2011;14: 608-615.

59 Berntgen M, Gourvil A, Pavlovic M, Goettsch W, Eichler HG, Kristensen FB: Improving the contribution of regulatory assessment reports to health technology assessments - a collaboration between the European Medicines Agency and the European network for Health Technology Assessment. Value Health 2014; 17:634-641.

60 Henshall C, Mardhani-Bayne L, Frønsdal KB, Klemp M: Interactions between health technology assessment, coverage, and regulatory processes: emerging issues, goals, and opportunities. Int J Technol Assess Health Care 2011;27:253-260.

61 Frønsdal K, Pichler F, Mardhani-Bayne L, Henshall C, Røttingen JA, Mørland B, Klemp $\mathrm{M}$ : Interaction initiatives between regulatory, health technology assessment and coverage bodies, and industry. Int $\mathrm{J}$ Technol Assess Health Care 2012;28:374-381.

62 European Medicines Agency: Adaptive pathways to patients: report on the initial experience of the pilot project. EMA/758619/2014. Accessible at http://www.ema.europa.eu/ docs/en_GB/document_library/Report/2014/12/WC500179560.pdf.

63 Shaping European Early Dialogues (SEED). Accessible at http://www.earlydialogues.eu/ has/ (accessed October 8, 2015).

64 European network for Health Technology Assessment (EUnetHTA). Accessible at http://www.eunethta.eu/ (accessed October $8,2015)$.

65 Ramsey SD, Willke RJ, Glick H, Reed SD, Augustovski F, Jonsson B, Briggs A, Sullivan SD: Cost-effectiveness analysis alongside clinical trials II - an ISPOR Good Research Practices Task Force report. Value Health 2015;18: 161-172.

66 Eichler HG, Bloechl-Daum B, Abadie E, Barnett D, König F, Pearson S: Relative efficacy of drugs: an emerging issue between regulatory agencies and third-party payers. Nat Rev Drug Discov 2010;9:277-291.

67 Packer C, Simpson S, de Almeida RT: EuroScan International Network member agencies: their structure, processes, and outputs. Int J Technol Assess Health Care 2015;31:7885.

68 Wonder M: What can be gained from increased early-stage interaction between regulators, payers and the pharmaceutical industry? Expert Rev Pharmacoecon Outcomes Res 2014;14:465-467.
69 Morel T, Arickx F, Befrits G, Siviero P, van der Meijden C, Xoxi E, Simoens S: Reconciling uncertainty of costs and outcomes with the need for access to orphan medicinal products: a comparative study of managed entry agreements across seven European countries. Orphanet J Rare Dis 2013;8:198.

70 Tunis SR, Pearson SD: Coverage options for promising technologies: Medicare's "coverage with evidence development". Health Aff (Millwood) 2006;25:1218-1230.

71 Stafinski T, McCabe CJ, Menon D: Funding the unfundable: mechanisms for managing uncertainty in decisions on the introduction of new and innovative technologies into healthcare systems. Pharmacoeconomics 2010;28:113-142.

72 Garrison LP Jr, Towse A, Briggs A, de Pouvourville G, Grueger J, Mohr PE, Severens JL, Siviero P, Sleeper M: Performance-based risksharing arrangements - good practices for design, implementation, and evaluation: report of the ISPOR Good Practices for Performance-Based Risk-Sharing Arrangements Task Force. Value Health 2013;16:703-719.

73 Klemp M, Frønsdal KB, Facey K: What principles should govern the use of managed entry agreements? Int J Technol Assess Health Care 2011;27:77-83.

74 Ferrario A, Kanavos P: Managed entry agreements for pharmaceuticals: the European experience. Brussels, Belgium: European Medicines Information Network (EMINET). 2013. Accessible at http://ec.europa.eu/DocsRoom/ documents/7627/attachments/1/translations/en/renditions/pdf.

75 Leyens L, Richer É, Melien $\varnothing$, Ballensiefen W, Brand A: Available tools to facilitate early patient access to medicines in the $\mathrm{EU}$ and the USA: analysis of conditional approvals and the implications for personalized medicine. Public Health Genomics 2015;18:249-259.

76 Campbell SM, Godman B, Diogene E, Fürst J, Gustafsson LL, MacBride-Stewart S, Malmström RE, Pedersen H, Selke G, VlahovićPalčevski V, van Woerkom M, Wong-Rieger D, Wettermark B: Quality indicators as a tool in improving the introduction of new medicines. Basic Clin Pharmacol Toxicol 2015; 116:146-157.

77 Field MJ, Boat TF: Rare Diseases and Orphan Products, Accelerating Research and Development. Washington, DC, National Academies Press, 2010.

78 Lee P: Contracting to preserve open science: the privatization of public policy in patent law. Accessible at http://works.bepress.com/ peter_lee/3/.

79 Bruyaka O, Zeitzmann HK, Chalamon I, Wokutch RE, Thakur P: Strategic corporate social responsibility and orphan drug development: insights from the US and the EU biopharmaceutical industry. J Bus Ethics 2013;117:4565. 